\title{
Infection control strategy in orthodontic office
}

\author{
Shalaj Bhatnagar, Dinesh K. Bagga ${ }^{1}$, Payal Sharma², Piush Kumar², Rakesh Sharma ${ }^{2}$, \\ Vishal Singh ${ }^{2}$ \\ Department of Orthodontics and Dentofacial Orthopaedics, ITS Dental College, Greater Noida, \\ ${ }^{1}$ Orthodontics and Dentofacial Orthopaedics, Hindustan Dental College, ${ }^{2}$ ITS-Centre for \\ Dental Studies and Research, Muradnagar, Ghaziabad, Uttar Pradesh, India
}

\author{
Address for correspondence: \\ Dr. Shalaj Bhatnagar, \\ Department of Orthodontics and \\ Dentofacial Orthopaedics, \\ ITS Dental College, Greater Noida, \\ Uttar Pradesh, India. \\ E-mail: bhatnagardrshalaj@yahoo.in
}

\begin{abstract}
Effective and efficient infection control in the orthodontic office is essential for the safety of patients. A comprehensive infection control strategy must be implemented by the orthodontist without compromising on cost-effectiveness and time factor, that safeguards not only his own health but also of the auxiliary staff and even the community. It is also important to follow manufacturer's instructions for dental instruments and devices regarding sterilization to avoid damage to these items.
\end{abstract}

Key words

Infection control, orthodontic office, sterilization

\section{INTRODUCTION}

Orthodontists are exposed to a wide variety of microorganisms in orthodontic office by contaminated instruments, inhalation of aerosols or via percutaneous injuries with archwires, ligature wires, band material and other sharp cutting instruments. ${ }^{[1]}$ Hepatitis B virus can be transmitted via as little as $0.0004 \mathrm{ml}$ blood while HIV via $0.1 \mathrm{ml}$ blood. ${ }^{[2]} 1 \mathrm{ml}$ of gingival crevicular fluid contains 150 billion microorganisms and 6 billion microorganisms can be found in $1 \mathrm{ml}$ of saliva. ${ }^{[3]}$ The possibility of cross-contamination in the orthodontic office is from the patient to the dental team; from the dental team to the patient; from the patient to the patient and from the dental office to the community, including the dental team's families. ${ }^{[4,5]}$

Specific infection control recommendations have been put forward by agencies such as British Dental Association, ${ }^{[6]}$ American Dental Association ${ }^{[7]}$ and Center for Disease Control. ${ }^{[8,9]}$

In 1985, the Council of Dental Therapeutics stated that infection control programs should have four goals,

\begin{tabular}{|l|l|}
\hline \multicolumn{2}{|c|}{ Access this article online } \\
\hline Quick Response Code: & Website: \\
\hline & www.ejgd.org \\
\cline { 2 - 2 } & \\
\hline
\end{tabular}

1. Reduce the number of available pathogenic microbes to a level where the normal resistance mechanisms of the body can prevent infection, 2 . Break the cycle of infection and eliminate cross-contamination, 3 . Treat every patient as though capable of transmitting infection, 4. Protect patients and all dental personnel from infection and its consequences and protect all dental personnel from threat of mal-practice suit. ${ }^{[10]}$

\section{INFECTION CONTROL STRATEGY}

Each clinical practice must have a written infection control policy which must continually be upgraded with the latest recommendations and directives of the particular region/state/country where the practice is located. ${ }^{[6]}$ Infection control strategy involves various aspects.

I) Patient screening

II) Instrument processing

III) Personal protective and barrier technique

IV) Dental office design

V) Waste management

\section{Patient screening}

A patient with subclinical infection is a potential source of cross-contamination. Therefore, all the patients must be screened by obtaining the relevant medical and dental history from them and a physician must be consulted if doubt arises. ${ }^{[2,6]}$

\section{Instrument processing}

Instrument processing is done to prepare contaminated instruments for reuse while keeping instrument damage to a minimum. 
The following steps are undertaken, ${ }^{[5,11]}$

1. Holding (presoaking)

2. Pre-cleaning/pre-sterilization

3. Corrosion control, drying and lubrication

4. Packaging

5. Sterilization

6. Sterilization monitoring

7. Handling processed instruments

8. Instrument protection

\section{Holding (Presoaking)}

Typically enzymatic detergents are used to break down organic material and presoaking makes later processing easier by helping to prevent blood and other matter from drying on instruments. Extended presoaking for more than a few hours is not recommended, for this may enhance the corrosion of some instruments.

\section{Pre-cleaning}

Pre-cleaning reduces the number of microbes present and removes blood, saliva and other materials that may insulate microbes.

Manual scrubbing of instruments: All surfaces of instruments should be thoroughly brushed while the instruments are submerged in a cleaning solution to avoid spattering followed by thorough rinsing with a minimum of splashing.

Ultrasonic cleaning

Ultrasonic cleaning ${ }^{[12-14]}$ is preferred to manual scrubbing as it reduces direct contact of the contaminated instruments and the chances for cuts and punctures in the gloves. The time required ranges from about 5-15 minutes. Cleaning solution should be changed at least daily. Few instruments cannot be ultrasonically cleaned, like some high-speed hand pieces.

\section{Corrosion control, drying and lubrication}

Although rust inhibitors (e.g., sodium nitrite) can be sprayed on the instruments but the best approach is to sterilize with either dry heat or unsaturated chemical vapor sterilization, which does not cause rusting.

\section{Packaging}

Unpackaged instruments can be contaminated by dust or aerosols in the air, by improper handling or by contact with contaminated surface as soon as the sterilizer door is opened.

Packaging instruments in pouches or cassettes before the sterilization prevents them from becoming contaminated after sterilization during storage or while being distributed to chair side. Instruments should be dried thoroughly before packaging in paper or paper plastic sterilization wrap. The wrap should be sealed with tape that will withstand the heat process. (e.g., autoclave tape).
These are available in many different sizes, can be used in steam or unsaturated chemical vapor sterilizers and have chemical indicators printed directly on the pouch. Cassettes are available in stainless steel, aluminum, plastic and resin materials that can withstand steam, chemical vapor and dry heat sterilization. Gauze and cotton pieces are generally placed in stainless steel bins with vents before placement in the autoclave allowing the steam under pressure to penetrate the bins and upon removal from the autoclave these vents can be sealed to prevent the contamination of the cotton and gauze pieces by the external environment.

\section{Sterilization}

Sterilization is a process intended to kill all microorganisms and their spores and is the highest level of microbial destruction that can be achieved.

There are three types of sterilization processes used in dentistry

A) Heat sterilization

- Boiling water sterilization

- Dry heat sterilization

- Moist heat sterilization

- Rapid heat transfer sterilization

- Glass Bead sterilization

B) Gas sterilization

- Chemical vapor sterilization

C) Liquid chemical sterilization

The instruments can be categorized as critical, semi-critical and non-critical on the basis of risk of transmitting infection and level of disinfection required. Instruments or materials that penetrate the soft tissue or bone e.g., bands, ligatures, ligature directors etc., are labeled as critical. Instruments or materials that touch the mucosa e.g., mirror, cheek retractor, most orthodontic pliers like band forming pliers etc., are labeled as semi-critical. Critical and semi-critical instruments require high level of disinfection. Instruments or materials that touch the skin e.g., boon gauge, ligature tying pliers, arch forming pliers, torquing keys etc., are labeled as non-critical or least critical and they require intermediate or low level of disinfection.

Autoclave sterilization of hand pieces is one of the most rapid methods of sterilization. Chemical vapor pressure sterilization recommended for some types of handpieces apparently works well with ceramic-bearing handpieces, but it may impair others. Ethylene oxide (ETOX) gas is the gentlest method of sterilization used for handpieces. ${ }^{[4,5,15,16]}$

High speed evacuation tips (HVE) evacuate aerosolized pathogens along with excess saliva and water droplets thereby reducing the likelihood of spreading infectious diseases in the operatory. The HVE tips are supplied in both plastic and metal. Metal HVE tips are autoclavable and the plastic HVE tips are disposable. 


\section{Sterilization monitoring}

Sterilization monitoring is done to achieve sterility assurance by biological, chemical and physical monitoring. ${ }^{[17,18]}$

\section{Biological monitoring}

Biological monitoring tests the efficiency of sterilization. Biological indicators (BI) contain the bacterial endospores used for monitoring. Bacillus stearothermophilus spores are used for testing the efficiency of sterilization by autoclaving. Clostridium tetani spores and Bacillus subtilis spores are used for testing the efficiency of sterilization by dry heat. It involves processing highly resistant bacterial spores through the sterilizer and then culturing the spores to determine if they have been killed.

\section{Chemical monitoring}

Chemical monitoring involves the use of heat sensitive indicators that change color or physical form when exposed to certain temperatures such as autoclave tape, special marking on pouches and bags, chemical indicators strips, tabs or packets or tubes of colored liquid.

There are two types of chemical indicators, an external indicator on the outside of every pack, pouch or cassette to indicate that the item has been processed to certain temperature for some length of time and an internal indicator placed inside to assess if the instruments have been exposed to sterilizing conditions.

\section{Physical monitoring}

Physical monitoring of the sterilization process involves observing the gauges and displays on the sterilizer and recording the sterilizer temperature, pressure and exposure time. It must be remembered that sterilizer gauges and displays indicate the conditions in the sterilizer chamber rather that conditions within the packs, pouches or cassette being processed.

\section{Handling processed instruments}

Instrument sterility should be maintained until the sterilized packs, pouches or cassettes are opened for use at chair side.

Drying and cooling

Packs, pouches or cassette processed through small office steam sterilizer (or autoclave) must be allowed to dry before handling for the wet paper may "draw" microorganisms through the wrap or be easily torn when handled.

\section{Storage}

Storage of sterile packs for more than a few days at the most is uncommon in dentistry. Sterile packages should be stored in dry, enclosed, low dust areas away from heat sources.
Instrument packages should be checked for tears or puncture after cooling and just before use at chair side. If sterile packages become wet or are torn or punctured, sterility is compromised. The oldest sterile should be used first as long as the packaging material is intact. This is referred to as the "first in-first out" system of stock rotation. Small metal instruments, autoclaved packages in double-wrapped linen or double-wrapped plastic-paper combinations can be stored safely for at least 96 weeks. ${ }^{[19]}$ A maximum storage time might be considered as 1 month.

\section{Distribution}

Instruments from sterile packs or pouches can be placed on sterile, disposable or at least cleaned and disinfected trays as chair side. Sterilized instrument cassettes are distributed as and when required by the operator and should be opened by the chair side. Placing unwrapped or wrapped instruments in drawers or cabinets for direct use at chair side during patient care is not recommended. The drawers or cabinets and their contents are too easily contaminated from retrieval of items with saliva-coated fingers.

\section{Instrument protection}

Instrument processing can cause damage to instruments, but several steps could be taken to keep this at a minimum. Stainless steel instruments are least affected by corrosion from moisture and heat, but some clinicians prefer instruments with carbon steel rather than stainless steel cutting surfaces that may retain a sharp edge longer. Unfortunately, carbon steel items corrode and lose sharpness during steam sterilization. For example, tungsten carbide burs lose about $64 \%$ of their cutting efficiency after steam sterilization. Use of dip or spray rust inhibitors usually reduce corrosion but with repeated steam sterilization cycles, the items will be damaged. Carbon steel items are best sterilized in a non corrosion-producing environment such as dry heat or chemical vapor sterilizer. Every effort should be made to rinse away or remove biological debris, disinfecting or sterilizing solutions, chloride salts and highly alkaline detergents prior to heat processing.

\section{Personal protection and barrier technique ${ }^{[4,5,20]}$ Self-immunization}

Health care workers are at risk for exposure to and possible transmission of several vaccine preventable diseases such as hepatitis B virus (HBV), influenza, rubella, measles etc., and therefore they should be vaccinated. ${ }^{[5]}$

\section{Control of microorganisms}

An effective approach to the prevention of disease is to reduce the number of potentially dangerous microorganisms by barrier techniques as follows: Hand washing.

The skin harbors resident flora like Staphylococcus epidermidis, micrococci and diphtheroids. In addition 
pathogenic microorganisms that are present in blood, saliva and dental plaque can contaminate the hands of dental health care personnel. The fingernails are common areas for blood impaction and evidence strongly suggests that this blood is not easily removed by dentist's hand-washing techniques and may remain impacted under fingernails for 5 days or longer. ${ }^{[21]}$

Even the most carefully washed hands will not be totally free of resident or transient bacterial florae. ${ }^{[22]}$ Fingernails should be kept short and clean. Soaps containing chlorhexidine gluconate, parachlorometaxylenol (PCMX) or iodophors are effective and usually do not irritate the skin.

\section{Gloves}

Gloving does not replace hand washing. ${ }^{[23]}$ Hands must be washed before wearing the gloves and after the removal of gloves. Gloves are meant for single use. Reuse of gloves increases infection risks to dental personnel and to the patient. When gloves are torn, cut or punctured during the dental procedures, they should be immediately replaced. Gloves should be stored in a cool dark place. Based on their composition, they can be classified as latex gloves and non-latex Gloves.

Latex gloves are manufactured from the rubber tree sap, which is treated to give the kind of flexibility which is required while working after donning them. However, latex gloves have been shown to cause allergic reactions with the skin (allergic dermatitis) while the non-latex gloves on the other hand are non-allergic and are manufactured from synthetic rubber or vinyl.[22]

It has been estimated that nearly 19,000 bacteria can pass through a single glove defect in 20 minutes and the site of maximum punctures were detected on the thumbs (both hands) and the left index finger. ${ }^{[24]}$

\section{Masks}

Masks protect the mucous membranes of the mouth and nose from direct contamination of aerosols. Masks selected for use should have at least a 95\% bacterial filtering efficiency for small particle aerosols (3-5 $\mu \mathrm{m})$ and must be comfortable and fit well over the nose.

It is recommended that a new mask be worn for each patient and the mask be changed routinely at least once every hour and more often in the presence of heavy aerosol contamination.

\section{Protective eyewear}

Protective eyewear is indicated, not only to prevent physical injury, but also to prevent infection from aerosol. Of particular concern are the herpes simplex viruses and staphylococcus aureus. Contaminated protective eyewear should be washed thoroughly with soap and water, rinsed well and sterilized, if possible or disinfected in an agent that does not damage eyeglasses. Disposable eyeglasses for the patient also should be considered for protection from accidentally dropped instruments, chemical splashes and any another foreign object injury.

\section{Protective clothing}

Protective clothing such as reusable or disposable gowns, laboratory coats or uniforms should be worn to prevent contamination from blood or other body fluids. Protective clothing should be changed at least daily or as soon as it becomes visibly soiled. The patient's perception regarding infection control procedures also differ regarding the clinical attire of the dental healthcare team. ${ }^{[25]}$ Patients should be covered with sterile drape to prevent contamination of patient's clothing from saliva, blood and aerosol.

Barriers to reduce contaminated aerosols Chemical barriers

It has been shown that having the patient rinse his or her mouth with water before operative procedures can reduce the bacterial count in generated aerosols by $75 \%$. Brushing the teeth can reduce the bacterial count in aerosols by $90 \%$ and use of a mouthwash can reduce the bacterial count by $98 \%$. Chlorhexidine gluconate $(0.12 \%)$ rinses effect a prolonged suppression of oral microorganisms over a 5 hour period compared with other alcohol containing mouthwashes or water.

\section{Mechanical barrier}

The American National Standard-American Dental Association Specification No.47 (April 21, 1984) states that the water should not retract more than 2.032 centimeters back into hand piece to minimize cross-contamination between patients. Anti retraction valves should be inserted into the water hose. Flushing water through the hand piece lessens the chance of cross contamination. The hand piece should be autoclavable and chemically disinfected.

Surface asepsis

There are two general approaches to surface asepsis..$^{[4,5,20]}$ One is to clean and disinfect contaminated surfaces and the other is to prevent the surface from becoming contaminated in the first place by use of surface covers.

Surfaces that become contaminated during patient care by touching or by aerosols or spatter and that are involved in the care of the next patient should be cleaned and then disinfected using a disinfectant either by spraying or by using a saturated pad before the care of the next patient. Impressions, casts, registration bites, orthodontic appliances, various surrounding equipments/items such as dental chair, table, light handles, spittoon, three-way syringes etc., should be cleaned and disinfected. Equipments and items are usually wiped with $70 \%$ isopropyl alcohol. 
There are at least three keys things to look for in selecting a disinfectant

- It should be one that has been registered with the environmental protection agency (EPA)

- The product should be indicated for use as a surface disinfectant in health care facilities

- The product selected should be labeled as being tuberculocidal.

Many operatory surfaces e.g., light handles, chair switches, head rests, hand piece hoses, unit controls, bracket/instrument tables, hand piece shafts, air-water syringe controls become contaminated during patient care by dental aerosols, salivary spatter or contaminated fingers and are difficult or impossible to clean or disinfect. If these surfaces are not protected during treatment or disinfected after treatment, they may serve as sources for cross contamination of the next patient. An effective cover impermeable to water like impervious backed paper, aluminum foil or plastic covers should be used. One of the best ways to prevent patient to patient cross contamination is to use disposable items like gloves, masks, gowns, surface covers, saliva ejector tips, air water syringe tips, high-volume evacuator tips, some instruments, some burs, impression trays, fluoride gel trays, sharps containers and biohazard bags. Conventional orthodontic marking pencils cannot be autoclaved. Soaking or spraying the tips of pencils with disinfectants could be more effective than wiping.

Waterline asepsis ${ }^{[4,5,20,26,27]}$

The dental unit water supply systems (DUWS) are contaminated with micro organisms in the form of a biofilm coating inside of the water line in its stagnant areas due to retraction of water when negative pressure is built up upon switching off the system, thus contaminating the incoming water through hand pieces and air-water syringes. Hence all modern DUWS should be fitted with anti-retraction valves.

Flushing water through dental unit waterlines for 20 seconds may temporarily reduce the concentration of microbes in the water. Some units can be periodically flushed with a disinfectant (e.g., hypochlorite solution) to reduce the number of microbes in the effluent water.

A bacterial filter can be placed into the water line of the hand piece and air-water syringe hoses.

A new heat sterilizable independent water delivery system (AquaSept) has been introduced in the market which eliminates the possibility of DUWS contamination. Heat sterilization of all system components between patients prevents biofilm build-up and kills passively retracted pathogens.

\section{Dental office design ${ }^{[4,28,29]}$}

The success of an effective infection control program depends, in part, on proper office design. The following aspects should be addressed to treatment area (where direct intraoral mucosal contact occurs e.g., operatories and oral hygiene instruction areas), nontreatment area (where no direct patient contact occurs e.g., the reception room and lavatory) and treatment support area (where indirect patient contact occurs through handling contaminated items such as impressions, instruments and exposed films in the laboratory, instrument recirculation center and radiograph processing room respectively) with consideration to aesthetics, patient appeal and effect on productivity. ${ }^{[4,29]}$

Floor plan and traffic flow

Patient treatment areas generate the highest level of microbial laden spatter. These areas must be separated from the treatment support area as well as the non-treatment areas to reduce cross-contamination via air handling systems, patients, personnel and visitors.

Consultation areas should be located closest to the administrative and reception areas, followed by the hygiene/patient education room and full treatment operatories. Longer appointments should be scheduled in the most distant operatory with short visits scheduled in the first treatment rooms. This directs the heaviest flow of patient/visitor traffic away from extensive treatment and treatment support areas.

The IRC and the laboratory should be accessible to the treatment areas. Patient traffic areas should not include the laboratory and IRC. Direct access should be available from the reception area to the scheduled operatory. A utility room containing the central vacuum and air compressor is best located adjacent to the laboratory to provide access for cleaning of filters and traps. A private entrance for staff is desirable and should be located with the staff lounge and lavatory in a remote yet accessible area. The private office should be located away from treatment and support areas unless it will be used for patient consultations.

\section{Fixtures}

Sink faucets and soap or lotion dispensers should be foot or arm operated to minimize hand contact. Dispensers should be mounted on the wall to reduce handling. Electric eye sink faucets and dispensers may be an attractive alternative. Paper towel dispensers also pose a contamination dilemma. "No touch" wall mounted towel dispensers are preferred. Hand-controlled sink faucets, if present, should be turned off using a paper towel after hand washing and drying. Cloth towels should never be used, as they retain a high number of microbes and serve as a source of cross-contamination. Operatory design and use of materials.

The operatory is the treatment area that produces the 
highest level of pathogens, therefore all floors, walls, surfaces, cabinets, drawers and equipment must be made of smooth and seamless nonporous materials, which not only inhibit accumulation of microbes but also can be easily cleaned and disinfected.

Carpet should not be used in treatment or treatment support areas. Continuous roll hard vinyl floor covering has been recommended for several years. Where carpeting is used, it should be low pile, tightly woven synthetic fiber with no pad and glued directly to the subflooring. Wool or high pile carpets are difficult to clean and may attract large numbers of pathogens. Vinyl, glass, resin laminates, stainless steel or processed resins may be used for cabinets and counters. Dimethyl methylacrylate (Corian-Dupont) is a nonporous, non-staining material that will not chip, discolor or crack according to the manufacturer. It may be used for back splash, counters, cabinet fronts, dental cart top surfaces or sinks. It is also available as a coating for existing structures.

The operatory should be designed with adequate working area. Cabinetry must support small auxiliary equipment such as curing lights. These items should be protected from aerosol and spatter.

Work areas must have positive ventilation to control noxious vapors from various chemicals used in laboratory and sterilization areas but simultaneously transportation of microbes from one area to another via ventilation systems must be prevented by preventing recirculation of contaminated air. Drawers should be made of impervious materials and be easily removable for cleaning and disinfection. All instruments should be retrieved from the IRC and returned at the conclusion of the treatment.

Instrument recirculation center

The IRC serves as the nucleus of the office infection control program and therefore must be conveniently located to all treatment areas. The IRC must also be designed in an area that avoids direct patient traffic pathways.

The IRC serves the following needs:

a. Precleaning of all contaminated instrument

b. Drying, sorting and packaging items

c. Sterilization (heat and chemical)

d. Storage

\section{Waste management}

All employees must be knowledgeable of occupational safety and health administration (OSHA) regulations concerning blood-borne pathogens, hazardous materials and safe use of chemicals in the laboratory ${ }^{[4,5,30,31]}$ and the environmental protection agency (EPA) dealing with both workplace exposure levels to chemicals, heat and radiation and for discharge and final treatment of waste material.

Infectious waste management $t^{[5,20]}$

I. Blood in a liquid form

In the overwhelming number of areas, blood (even mixed with other fluids, such as saliva) can be poured into sink traps and the evacuation lines which should be thoroughly rinsed at least daily. A disinfectant solution should be drawn through the lines followed by final rinsing with water.

II. Pathologic waste (teeth and other tissue)

The potentially infectious pathologic waste (extracted teeth/ and associated tissue, blood soaked cotton, gauze, pellets, tissue coverings etc.) should be wrapped in autoclavable plastic/paper bag and autoclaved before disposal.

\section{Sharps}

Sharp items like injection needles, scalpel blades, broken glass, discarded archwires, cut steel ligature wires, band materials, bands etc., should be placed in closed, leak proof, puncture resistant containers (sharp boxes) and labeled with a biohazard symbol as well as color-coded for easy identification.

\section{CONCLUSION}

A comprehensive infection control strategy should be formulated and implemented by the orthodontist without compromising on cost-effectiveness and time factor, that safeguards not only his own health but also of the auxiliary staff and even the community.

\section{REFERENCES}

1. Bagramian RA, McNamara JA Jr. A prospective survey of percutaneous injuries in orthodontists. Am J Orthod Dentofac Orthop 1998;114:654-8.

2. Kumar V, Mogra S, Shetty SV. Hepatitis B: Facts and concerns to Orthodontist in India. J Ind Orthod Society 2007;41:30-4.

3. Checchi L, Matarasso S, Pirro P, D'Achille C. Topographical analysis of facial areas most susceptible to infection with transmissible diseases in dentists. Int $\mathrm{J}$ Periodontics Restorative Dent 1991;11:164-72.

4. Cottone JA, Terezhalmy GT, Molinari JA. Practical infection controlin dentistry. $2^{\text {nd }}$ ed. Baltimore. Williams and Wilkins; 1996.

5. Anil S, Samaranayake LP, Georges Krygier. Practical infection controlin dentistry. $1^{\text {st }}$ ed. Delhi AITBS Pub; 1999.

6. British Dental Association. Infection Control in Dentistry. BDA Advice Sheet A12. London: British Dental Association; 2003.

7. ADA Council on Scientific Affairs and ADA Council on Dental Practice. Infection Control Recommendations for the dental office and dental laboratory. J Am Dent Assoc 1996;127:672-80.

8. Centers for Disease Control and Prevention. Recommended Infection Control Practices for Dentistry. MMWR Recomm Rep 1993;42:1-12.

9. Centers for Disease Control. Recommended Infection Control Practices for Dentistry. MMWR Morb Mortal Wkly Rep 1986;35:237-42.

10. Council on Dental Therapeutics and Council on Prosthetic Services and Dental Laboratory Relations. Guidelines for infection control in 
the dental office and the commercial dental laboratory. J Am Dent Assoc 1985;110:969-72.

11. Miller $\mathrm{CH}$. Cleaning, sterilization and disinfection. Basics of microbial killing for infection control. J Am Dent Assoc 1993;124:48-56.

12. Bentley EM. The value of ultrasonic cleaners in dental practice. Br Dent J 1994;177:53-6.

13. Bentely EM, Sarll DW. Improvements in cross-infection control in general dental practice. Br Dent J 1995;179:19-21.

14. Spolyar JL, Johnson CG, Head R, Porath L. Ultrasonic cold disinfection. J Clin Orthod 1986;20:852-3.

15. Owen $\mathrm{AH} 3^{\text {rd }}$. Current orthodontic asepsis. J Clin Orthod 1990;24:417-26.

16. Sturdevant C, Roberson TM. Art and science of operative dentistry. $4^{\text {th }}$ ed. Mosby; 2004. p. 371-82.

17. Palenik CJ, Burke FJ, Coulter WA, Cheung SW. Improving and monitoring autoclave performance in dental practice. Br Dent $\mathrm{J}$ 1999;187:581-4.

18. Miller $\mathrm{CH}$, Sheldrake MA. The ability of biological indicators to detect sterilization failures. Am J Dent 1994;7:95-7.

19. Bhumisirkul W, Bhumisirkul P, Pongchairerks P. Long-term storage of small surgical instruments in autoclaved packages. Asian J Surg 2003;26:202-4.

20. Miller C, Paelnik CJ. Infection Control and Management of Hazardous Materials for the Dental Team. $3^{\text {rd }}$ ed. CV Mosby Co; 2005.

21. Allen AL, Organ RJ. Occult blood accumulation under the Fingernails. A mechanism for the spread of blood borne infection. J Am Dent Assoc 1982;105:455-9.

22. Gonzalez E, Naleway C. Assessment of the effectiveness of glove use as a barrier technique in the dental operatory. J Am Dent Assoc
1988;117:467-9.

23. Gobetti JB, Cerminaro M, Shipman C Jr. Handasepsis: The efficacy of different soaps in the removal of bacteria from sterile, glovedhands. J Am Dent Assoc 1986;113:291-2.

24. ADA Council on Scientific Affairs. Non-sterile latex examination gloves. J Am Dent Assoc 2002;133:225-7.

25. Burke FJ, Lewis HG, Wilson NH. The incidence of puncture in gloves worn during orthodontic clinical practice. Am J Orthod Dentofacacial Orthop 1991;99:477-81.

26. Shulman ER, Brehm WT. Dental clinical attire and infection-control procedures. J Am Dent Assoc 2001;132:508-16.

27. Porteous NB, Redding SW, Thompson EH, Grooters AM, De Hoog S, Sutton DA. Isolation of an unusual fungus in treated dental unit waterlines. J Am Dent Assoc 2003;134;853-8.

28. Depaola LG, Managan D, Mills S, Costerton W, Barbeau J, Shearer B, et al. A review of the science regarding dental unit waterlines. J Am Dent Assoc 2002;133;1199-206.

29. Hamula W. Orthodontic Office Design. Planning a Sterilization Area. J Clin Orthod 1991;25:375-81.

30. Unthank M. Dental office planning. J Am Dent Assoc 1999;130:1579-82.

31. Park K. Preventive and social medicine. $19^{\text {th }}$ ed. Jabalpur Banarsidas Bhanot Publishers; 2007. p. 644-50.

How to cite this article: Bhatnagar S, Bagga DK, Sharma P, Kumar P, Sharma R, Singh V. Infection control strategy in orthodontic office. Eur $\mathrm{J}$ Gen Dent 2013;2:1-7.

Source of Support: Nil, Conflict of Interest: None declared.

Announcement

\section{Android App}

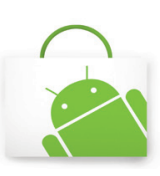

Download

Android application
A free application to browse and search the journal's content is now available for Android based mobiles and devices. The application provides "Table of Contents" of the latest issues, which are stored on the device for future offline browsing. Internet connection is required to access the back issues and search facility. The application is compatible with all the versions of Android. The application can be downloaded from https://market.android.com/details?id=comm.app.medknow. For suggestions and comments do write back to us. 